\title{
DESEMPENHO DE LINHAGENS DE ABÓBORAS NO OESTE GOIANO, BRASIL
}

Lucas Jorge dos Santos¹, Bárbara Miranda Borges², Aldo Max Custódio³, Flavio Lopes Claudio ${ }^{4}$, Alexandra Almeida Gléria ${ }^{5}$, Guido Calgaro Junior ${ }^{6}$, Tiago do Prado Paim ${ }^{7}$, Estenio Moreira Alves ${ }^{8}$

\begin{abstract}
RESUMO - As abóboras possuem papel fundamental na alimentação humana. Trata-se de alimento com características físico-químicas favoráveis a ingestão de nutrientes, vitaminas e carotenoides. Assim, objetivou-se avaliar o desempenho fitotécnico de linhagens de abóboras no município de Iporá, Goiás, Brasil. O delineamento experimental foi em blocos casualizados com cinco tratamentos e cinco repetições. Os tratamentos de referência foram compostos por três variedades comerciais: 'Rajada Seca Melhorada', 'Bahiana Tropical' e 'Itapuã 301 (Jacararezinho)' e duas linhagens experimentais de abóbora: 'LA 16B - F1' e 'LA 26C - F1'. As linhagens foram obtidas a partir de autofecundação (Homozigose) a partir de progenitores previamente selecionados do banco ativo de germoplasma do IF Goiano, Campus de Iporá. As parcelas foram compostas por cinco plantas. Os resultados demonstram que as variedades 'Seca Rajada Melhorada' e 'Itapuã 301 (Jacarezinho)' apresentaram um grande potencial produtivo. Nota-se a necessidade de realizar mais cruzamentos endogâmicos nas linhagens avaliadas com intuito de aprimorara-las e utilizá-las futuramente em sistemas produtivos locais. Conclui-se que as linhagens carecem de continuidade na seleção, pois apresentam potencial produtivo competitivo.
\end{abstract}

Palavras chave: Biometria de frutos, Cucurbita moschata, Prolificidade, Produtividade.

\section{PERFORMANCE OF CULTIVARS AND LINES OF PUMPKINS IN THE WEST THE STATE OF GOIAS, BRAZIL}

\begin{abstract}
Pumpkins play a key role in human nutrition. It is food with physicochemical characteristics favorable to the ingestion of nutrients, vitamins and carotenoids. The objective of this study was to evaluate the breeding performance of pumpkin lines in the municipality of Iporá, Goiás, Brazil. The experimental design was a randomized block with five treatments and five replicates. The reference treatments were composed of three commercial varieties: 'Rajada Seca Enhanced', 'Bahiana Tropical'and 'Itapuã 301 (Jacararezinho)' and two experimental lines of pumpkin: 'LA 16B - F1' and 'LA 26C - F1'. The lines were obtained from self-fertilization (Homozigose) from parents previously selected from the active germplasm bank of the Goiano IF, Campus Iporá. The plots were composed of five plants. The results demonstrate that the varieties 'Secada Rajada Melhorada' and 'Itapuã 301 (Jacarezinho)' presented great productive potential. Note the need to perform more inbreeding crosses in the lineages evaluated to improve them and use them in future in local productive systems. Therefore, we conclude that the lineages lack continuity in the selection since they do not present competitive productive potential.
\end{abstract}

Keywords: Fruit biometry, Cucurbita moschata, Productivity, Prolificacy.

\footnotetext{
${ }^{1}$ Graduando em agronomia, Bolsista ITI-A e IEX/CNPq - Instituto Federal Goiano, Campus Iporá.

${ }^{2}$ Téc. em Agropecuária, Graduanda em agronomia, voluntária - Instituto Federal Goiano, Campus Iporá.

${ }^{3}$ Professor, Engenheiro Agrônomo, Mestre em Agroecologia, Bolsista EXP-B/CNPq - Instituto Federal de Rondônia, Campus Colorado do Oeste.

${ }^{4}$ TAE, Zootecnista, Mestre em Des. Rural Sustentável, Instituto Federal Goiano, Campus Iporá.

${ }^{5}$ TAE, Técnico em Agropecuária, Gestor do Agronegócio, Instituto Federal Goiano, Campus Iporá.

${ }^{6}$ TAE, Técnico em Agropecuária, Adm. rural, Mestrando em Bioenergia e Grãos, Instituto Federal Goiano, Campus Rio Verde/Iporá.

${ }^{7}$ TAE, Médico Veterinário, Doutorando em Ciência Animal, Instituto Federal Goiano, Campus Iporá.

${ }^{8}$ TAE, Engenheiro Agrônomo, Mestre em Agroecologia, Doutorando em Ciências Agrárias, Instituto Federal Goiano, Campus Rio Verde/Iporá. Rodovia GO 060, km 222, Fazenda Escola-ULEP, CEP 76.200-000, Iporá, Goiás. estenio.moreira@ifgoiano.edu.br
} 


\section{INTRODUÇÃO}

Há variadas espécies no gênero Cucurbita, com destaque para as espécies moschata, maxima e pepo que diferem no formato, tamanho, coloração, casca, polpa, textura, teor de amido, teor de matéria seca e sabor, que representa maiores valores nutricionais $\mathrm{e}$ agro-econômicos, devido à presença de nutrientes voltados a alimentação humana e animal (Filgueira, 2008).

Dentre as vantagens do uso na alimentação, podemos citar a presença de vitamina $\mathrm{A}$ em quantidades significativas. A polpa contém em média de $0,2 \%$ de lipídios, 1,3\% de proteínas, $20 \mathrm{mg}$ de cálcio e 4,6\% de carboidratos totais, sendo que $2,7 \%$ correspondem a fibras. Suas sementes possuem propriedades farmacológicas, com potencial de prevenção de afecções da próstata (Rodriguez-Amaya, 2008).

Outro fator relevante das abóboras é a concentração de compostos benéficos ao organismo como: carotenóide, pigmentos de propriedades antioxidantes, que são atribuídos à coloração amarelo-laranjada ou até mesmo vermelha da polpa. Carotenóides são compostos presentes nos alimentos de fundamental importância para o bem-estar da saúde. Dentre os benefícios do fruto das abóboras, está a redução da deficiência em vitamina A. fortalecimento do sistema imunológico, prevenindo contra câncer, doenças cardiovasculares, degeneração macular e catarata, (Rodriguez-Amaya, 2008; Shi et al., 2013).

Além das propriedades químicas da polpa, suas sementes são ricas em proteínas, lipídios e fibras, que também contém compostos bioativos e antinutricionais como: ácidos graxos essenciais, tocoferóis, carotenóides, compostos fenólicos, fitosteróis, cucurbitacinas, cianetos, inibidores de tripsina e saponinas trazendo benefícios à saúde. Todavia, a realização de processamento térmico, como o cozimento reduz a concentração de compostos antinutricionais, viabilizando o consumo e utilização das sementes para a extração de óleos não convencionais, que são capazes de participar na composição de alimentos industrializados e até mesmo para condimentos (Veronezi \& Jorge, 2012).

Embora as abóboras sejam apreciadas na culinária e saudadas pelos variados atributos nutracêuticos, o acesso dos consumidores aos frutos depende da produtividade a campo e consequentemente do total produzido. A indisponibilidade e a dependência de importação de abóboras convergem contrárias a segurança alimentar e aos princípios de produção agroecológicos em nível regional e até mesmo nacional.

Portanto, conhecer o comportamento de diferentes genótipos é fundamental para a construção e modificação gradativa ao longo do tempo dos agroecossistemas produtivos, visto que as formas de manejo e administração de ecossistema com presença das populações locais envolvidas, sejam estes agrícolas e ou urbanas (Caporal $\&$ Costabeber, 2004).

Neste sentido, desenvolver sistemas produtivos e avaliar genótipos fazem parte dos caminhos a serem percorridos pela pesquisa para fomentar a introdução e produção local. Esta por sua vez, é fundamental para a independência e aumento da segurança alimentar regional no primeiro plano. Muito embora, dependendo do plano de observação a produção local significa segurança a uma nação.

Assim, buscando o empoderamento dos agricultores familiares, o desenvolvimento regional e por consequência nacional, objetivou-se avaliar o desempenho fitotécnico de linhagens de abóboras selecionadas a partir de provenientes de progenitores do banco ativo de germoplasma do Instituto Federal Goiano, Campus Iporá, município de Iporá, Goiás, Brasil.

\section{MATERIAL E MÉTODOS}

O ensaio foi conduzido à campo no setor de olericultura da fazenda escola do Instituto Federal Goiano, Campus de Iporá, Goiás, em solo com as seguintes características químicas: $\mathrm{pH}=4,7 ; \mathrm{Ca}\left(\mathrm{cmol}_{\mathrm{c}} \cdot \mathrm{dm}^{-3}\right)=$ 1,$2 ; \mathrm{Mg}\left(\mathrm{cmol}_{\mathrm{c}} \cdot \mathrm{dm}^{-3}\right)=0,5 ; \mathrm{Ca}+\mathrm{Mg}=1,7 ; \mathrm{Al}\left(\mathrm{cmol}_{\mathrm{c}} \cdot \mathrm{dm}^{-3}\right)$ $=0.0, \mathrm{H}+\mathrm{Al}\left(\mathrm{cmol}_{\mathrm{c}} \cdot \mathrm{dm}^{-3}\right)=2,5 ; \mathrm{CTC}\left(\mathrm{cmol}_{\mathrm{c}} \cdot \mathrm{dm}^{-3}\right)=4,61$; $\mathrm{P}($ Melichl $)\left(\mathrm{mg} / \mathrm{dm}^{3}\right)=11,0 ; \mathrm{K}\left(\mathrm{cmol}_{\mathrm{c}} \cdot \mathrm{dm}^{-3}\right)=0,41 ; \mathrm{K}$ $\left(\mathrm{mg} / \mathrm{dm}^{3}\right)=160,0 ;$ Mat. Org. $(\%)=1,2$; Sat.Al $(\mathrm{M} \%)$ $=0.0$, Sat. Base $(\mathrm{V} \%)=46,0 ; \mathrm{Ca} / \mathrm{Mg}=2,4 ; \mathrm{Ca} / \mathrm{CTC}$ $=26,1 \% ; \mathrm{Mg} / \mathrm{CTC}=10,9 \% ; \mathrm{K} / \mathrm{CTC}=8,9 \%$. A granulometria determinada do solo foi de $28,0 \%$ de argila, $15,0 \%$ de silte e $57,0 \%$ de areia.

O delineamento experimental foi em blocos casualizados com cinco tratamentos e cinco repetições. Os tratamentos compostos por três variedades comerciais: 'Rajada seca melhorada'; 'Bahiana tropical' e 'Itapuã 301 (Jacararezinho)' e duas linhagens Linhagem de abóbora ('LA 16B - F1') e (LA 26C - F1'). As linhagens 
foram obtidas a partir do banco de germoplasma do IF Goiano, Campus de Iporá. As parcelas foram compostas por cinco plantas.

Utilizou-se de sistema de irrigação por gotejamento, com um gotejador por cova, mantendo o solo próximo à capacidade de campo. As mudas de abóbora foram produzidas em bandejas de plástico (200 células), utilizando-se substrato comercial. A adubação de base foi incorporada obedecendo ao espaçamento de 2,5 $\mathrm{x} 1,0 \mathrm{~m}$ totalizando assim uma densidade equivalente a 4000 plantas por hectare.

O preparo do solo foi realizado em 08/10/2015 com duas operações de gradagem intermediária 28" e uma gradagem niveladora 22". A abertura das covas, adubação de base e semeio das bandejas realizadas em 08/10/ 2015. Sendo que as mudas foram transplantadas para o local de cultivo em 14/10/2015, na fase cotiledonar. Utilizou-se 2 L de composto orgânico (Tabela 1) e 300 $\mathrm{g}$ de superfosfato simples.cova ${ }^{-1}$ adaptado Ribeiro et al. (1999). Aplicou-se em cobertura $45 \mathrm{~kg} \cdot \mathrm{ha}^{-1}$ de N (Uréia) e $20 \mathrm{~kg} \cdot \mathrm{ha}^{-1}$ de $\mathrm{K}_{2} \mathrm{O}$ (Cloreto de potássio) divididos em duas aplicações, aos 32 e 49 dias após o semeio das culturas.

Realizou-se a colheita 105 dias após o semeio. Determinou-se a produtividade $\left(\mathrm{Mg}^{-h^{-1}}\right)^{-1}$, índice de prolificidade, massa média dos frutos $(\mathrm{kg})$, comprimento $(\mathrm{cm})$, diâmetro $(\mathrm{cm})$ e relação comprimento:diâmetro (C:D) das abóboras. Os dados foram submetidos à análise de variância, quando significativo, aplicou-se o teste “t” ( $\mathrm{P}<0,05)$ (Silva \& Azevedo, 2016).

\section{RESULTADOS E DISCUSSÃO}

Dentre os genótipos estudados a variedade comercial 'Rajada Seca Melhorada' apresentou a maior

Tabela 1 - Atributos e composição química do composto orgânico

\begin{tabular}{lc}
\hline Nutrientes & Teores \\
\hline Nitrogênio $(\mathrm{N})$ & $2,40 \%$ \\
Fósforo $\left(\mathrm{P}_{2} \mathrm{O}_{5}\right)$ & $1,40 \%$ \\
Fósforo $(\mathrm{P})$ & $0,62 \%$ \\
Potássio $(\mathrm{K})$ & $0,80 \%$ \\
Cálcio $(\mathrm{Ca})$ & $2,36 \%$ \\
Magnésio $(\mathrm{Mg})$ & $0,42 \%$ \\
Densidade & 0,60 \\
Matéria seca & $50,00 \%$ \\
\hline
\end{tabular}

produtividade 35,33 Mg.ha-1 ${ }^{-1}$, seguida pela 'Itapuã 301 (Jacarezinho)' com 21,53 Mg.ha ${ }^{-1}$. Os demais genótipos obtiveram produtividade iguais variando de $5 \mathrm{a} 9 \mathrm{Mg}^{-h^{-1}}$, sem diferenças das linhagens para a variedade 'Bahiana Tropical' (Tabela 2).

Esse resultado embora não superior a todos os genótipos comerciais denota potencial produtivo. Ressalta-se ainda que a variedade 'Rajada Seca Melhorada' é de grupo de abóboras gigantes. Assim, igualar-se as variedades 'Bahiana Tropical' é satisfatório, porém há necessidade de seguir com a seleção e cruzamentos endogâmicos com propósito de melhor o desempenho produtivo das linhagens.

A produtividade das linhagens 'LA 26C F1' e 'LA 16B F1' foram 8,94 e 5,84 Mg.ha' ${ }^{-1}$ não deferindo. De acordo com Resende et al. (2013), os acessos A612 e A422 alcançaram uma produtividade de 17,3 e 15,2 $\mathrm{Mg} \cdot \mathrm{ha}^{-1}$ superiores à média nacional $\left(4,4 \mathrm{Mg} \cdot \mathrm{ha}^{-1}\right) \mathrm{e}$ a mundial de abóbora $\left(13,4 \mathrm{Mg} \cdot \mathrm{ha}^{-1}\right)$.

Já as linhagens LA 26C e LA 16B demonstraram serem superiores à média nacional, porém foi inferior à média mundial de abóbora. Demonstrando potencial produtivo a nível local, bem como, para continuidade na seleção e melhoramento com propósito de igualar aos demais genótipos comerciais.

A produtividade da variedade 'Itapuã 301 (Jacarezinho)' foi superior (Tabela 2) ao descrito por Resende et al. (2013), que testaram diferentes espaçamentos, resultando em uma produtividade de 12,20 Mg.ha-1 . Já Santos et al. (2015) obtiveram média de $15,15 \mathrm{Mg} \cdot \mathrm{ha}^{-1}$ com genótipo similar. Estes resultados corroboram em prol do potencial de cultivo deste genótipo na região de estudo.

A produtividade descrita por Mendes et al. (2017) das variedades 'Rajada Seca Melhorada', 'Itapuã 301 (Jacarezinho)' e 'Bahiana Tropical' não deferiram entre si. Estes resultados são divergentes dos apresentados na tabela 2. Esta divergência reforça a necessidade de pesquisas aplicadas a responder o comportamento produtivo ao longo do ano dos genótipos, uma vez que ambos os ensaios foram realizados no mesmo ambiente, divergindo época do ano e o ano, princípios estes corroborados por Santos et al. (2015).

De acordo com Latifi et al. (2012), a densidade de abóboras nos cultivos é um fator importante que afeta principalmente a produtividade, diante deste fator 
Tabela 2 - Produtividade, índice de prolificidade e massa média das abóboras de diferentes genótipos de abóbora (C. moschata). Iporá - GO, 2015

\begin{tabular}{lccc}
\hline Genótipos & Produtividade $\left(\mathrm{Mg}^{-h^{-1}}\right)$ & Índice de prolificidade & Massa das abóboras $(\mathrm{kg})$ \\
\hline Rajada Seca Melhorada & $35,33 \mathrm{a}$ & $1,25 \mathrm{c}$ & $6,97 \mathrm{a}$ \\
Itapuã 301 (Jacarezinho) & $21,53 \mathrm{~b}$ & $2,85 \mathrm{a}$ & $2,16 \mathrm{~b}$ \\
Bahiana Tropical & $9,21 \mathrm{c}$ & $1,05 \mathrm{c}$ & $1,90 \mathrm{bc}$ \\
LA 26C IF Goiano & $8,94 \mathrm{c}$ & $1,90 \mathrm{bc}$ & $1,17 \mathrm{~cd}$ \\
LA 16B IF Goiano & $5,84 \mathrm{c}$ & $2,20 \mathrm{ab}$ & $0,62 \mathrm{~d}$ \\
CV (\%) & 27,04 & 32,54 & 21,90 \\
\hline
\end{tabular}

Na comparação entre as médias letras distintas na coluna representa diferenças entre as médias pelo teste " $\mathrm{t}$ " $(\mathrm{P}<0,05)$.

Tabela 3 - Dados referentes ao comprimento, diâmetro e relação comprimento: diâmetro das abóboras de diferentes genótipos de abóbora (C. moschata). Iporá - GO, 2015

\begin{tabular}{lccc}
\hline Genótipos & Comprimento $(\mathrm{cm})$ & Diâmetro $(\mathrm{cm})$ & Relação C:D \\
\hline Rajada Seca Melhorada & $52,51 \mathrm{a}$ & $18,46 \mathrm{a}$ & $2,84 \mathrm{a}$ \\
Itapuã 301 (Jacarezinho) & $12,68 \mathrm{bc}$ & $17,28 \mathrm{~b}$ & $0,73 \mathrm{~d}$ \\
Bahiana Tropical & $9,58 \mathrm{c}$ & $17,95 \mathrm{ab}$ & $0,54 \mathrm{e}$ \\
LA 26C IF Goiano & $13,35 \mathrm{~b}$ & $12,78 \mathrm{c}$ & $1,04 \mathrm{c}$ \\
LA 16B IF Goiano & $13,60 \mathrm{~b}$ & $10,43 \mathrm{~d}$ & $1,30 \mathrm{~b}$ \\
CV (\%) & 11,03 & 3,86 & 8,38 \\
\hline
\end{tabular}

Na comparação entre as médias letras distintas na coluna representa diferenças entre as médias pelo teste "t" $(\mathrm{P}<0,05)$.

pode-se afirmar o motivo da diferença da produtividade que pode ser em função do espaçamento. A prolificidade mencionada por Resende et al. (2013) foi de 4,70 para 'Itapuã 301 (Jacarezinho)', superior ao encontrado no presente trabalho. Ressalta-se que o melhor índice de prolificidade foi de 2,85 obtido pela variedade 'Itapuã 301 (Jacarezinho)' e 2,20 referentes a linhagem 'LA 26C F1' do IF Goiano.

Os demais genótipos de abóboras confrontados neste trabalho (Tabela 2) apresentaram um índice de prolificidade inferior aos descrito por Resende et al. (2013), que obteve uma média de prolificidade de 3,0 a 4,6 com os acessos: A612; A620; A422 e A627.

Outrora, Santos et al. (2015) atribuem estas variações aos efeitos das características típicas do ambiente de cultivo. Estes descrevem resultados diferentes para índices de prolificidade, variando de 1 a 5 frutos por planta a partir dos mesmos genótipos em ambientes diferentes.

A abóbora 'Rajada Seca Melhorada' obteve a maior massa fresca com 6,97 kg por fruto, deferiu da 'Itapuã 301 (Jacarezinho)' com $2,16 \mathrm{~kg}$. fruto ${ }^{-1}$, que por sua vez não difere do material 'Bahiana Tropical'. Estes valores são bem próximos aos descritos por Ramos et al. (2010) e Resende et al. (2013).
Os demais genótipos não diferiram, variando entre 0,62 a 1,17 kg.fruto ${ }^{-1}$. Observa-se que as linhagens 'LA 16B F1' e 'LA 26C F1', apresentam, massa menor com potencial de uso comercial in natura. Já a 'Seca Rajada Melhorada' é mais apreciada para produção de doces. Portanto, embora essa característica seja quantitativa, é muito importante como fator qualitativo no mercado consumidor.

A 'Rajada Seca Melhorada' foi diferente estatisticamente tanto para as características de comprimento, diâmetro e a relação entre ambas, quando comparadas entre os demais materiais estudados, (Tabela 3). Os resultados obtidos por Mendes et al. (2017) \{29,83 e $14,39 \mathrm{~cm}$ para comprimento e diâmetro, respectivamente $\}$, com o mesmo cultivar são inferiores, provavelmente as condições edafoclimáticas influenciaram no desenvolvimento deste cultivar e por conseqüência destas variáveis (Santos et al., 2015).

Segundo Lima Neto (2013), a abóbora Jacarezinho apresentou frutos cujo comprimento e diâmetro médio foi de 16,9; 17,6 cm, valores bem próximos aos descritos neste trabalho (tabela 3), muito embora, sejam superiores aos obtidos por Mendes et al. (2017), cujos valores foram 8,99 e 13,95 cm para comprimento e diâmetro, respectivamente. 
A variedade 'Bahiana Tropical' apresentou comprimento igual a $9,58 \mathrm{~cm}$ e diâmetro de $17,95 \mathrm{~cm}$, inferior aos demais genótipos, porém ao se comparar com Mendes et al. (2017), apresenta comprimento e diâmetro muito próximos de 11,41 e 17,97 cm.

As linhagens 'LA26CF1'e 'LA 16B F1'não diferiram em comprimento e diâmetro, diferindo da 'Rajada seca melhorada' e da 'Bahiana Tropical'. Entretanto, foi igual ao material 'Itapuã 301 (Jacarezinho)'. Freitas et al. (2014), trabalhando com a linhagem (ABO 312-1) de abóbora (C. moschata) braquítica, pertencente ao Banco de Germoplasma no estado de São Paulo, obteve 8,8 e 25,0 cm de comprimento e diâmetro, divergindo das linhagens 'LA 26 C F1' e 'LA16 B F1' que apresentaram 13,35 e 12,78 cm e 13,60 e 10,43 cm para comprimento e diâmetro. Resultados como estes são esperados devido a variabilidade genética entre acessos, linhagens e variedades de abóboras cultivadas.

A relação comprimento diâmetro (C:D) diferiu para todos os genótipos, até mesmo as variedades comerciais 'Itapuã 301 (Jacarezinho)' e 'Bahiana tropical', selecionados e produzidos para atender mercados muito similares. Desta forma observa-se que esta característica numérica remete ao formato do fruto, desde achatados $(<1,0)$, redondos $(=1,0)$ e compridos $(>1,0)$, podendo ser utilizada como forma quantitativa de descrever parcialmente uma característica qualitativa. Sugeremse avaliações futuras com propósito de validar está variável junto aos consumidores.

Há de se considerar que resultados locais são fundamentais na construção do alicerce produtivo regionais. São nos arranjos produtivos locais que formam as produções de abóboras. Estes arranjos dependem do empoderamento por meio de informações cientificas capazes de orientar os produtores agro-familiares desde a escolha da variedade a ser cultivada até a consolidação do atendimento prioritário do consumo local.

Mercados locais por sua vez devem ser prioridades desde a variedade como descrito anteriormente, devido a capacidade de reduzir a dependência por transportes rodoviários extensos, melhora a distribuição de renda regional e fomento a segurança alimentar. Fatores estes, também responsáveis por reduzir a pegada ambiental dos alimentos produzidos.

É importante ainda, considerar que avaliações qualitativas também são necessárias, a fim de aferir valor e mérito de produtividade por meio da qualidade das abóboras produzidas. Dentre as avaliações potenciais cita-se os carotenoides totais, atributo apontado para selecionar recursos genéticos de cucurbitáceas, com potencial promissor para determinar valor qualitativo (Souza et al., 2012).

\section{CONCLUSÕES}

Conclui-se que há potencial produtivo de produzir abóboras das variedades 'Seca rajada melhorada' e 'Itapuã 301 (Jacarezinho)' e que há necessidade de continuidade no melhoramento das linhagens avaliadas para uso nos sistemas produtivos locais, pois ainda não são competitivas frente as algumas variedades comerciais.

\section{AGRADECIMENTOS}

Agradecemos ao Instituto Federal Goiano, Campus Iporá e ao MCTI/MAPA/CNPq (Processo 473115/20140) pelo auxílio financeiro e concessão de bolsas.

\section{LITERATURACITADA}

CAPORAL, F.R.; COSTABEBER, J.A. Agroecologia e extensão rural: Contribuições para a promoção do desenvolvimento rural sustentável. Brasília: MDA/SAF/DATER-IICA, 2004.

FILGUEIRA, F.A.R. Novo manual de olericultura: Agrotecnologia moderna na produção e comercialização de hortaliças. 3.ed. Viçosa: Editora da Universidade Federal de Viçosa, 2008. 421p.

FREITAS, P.G.; CLAUDIO, M.T.R.A.; TAVARES, E.B.; MAGRO, F.O.; CARDOSO, A.I.I.; BARDIVIESSO, E.M. Poda apical para produção de frutos e sementes de abóbora.Agro@ mbiente On-line, v.8, n.2, p.230-237, 2014. http://dx.doi.org/10.18227/19828470ragro.v8i2.1891

LATIFI, M.; BARIMAVANDI, A.; SEDAGHARHOOR, S.; LIPAYI, S.R. Sowing date and plant population effects on seed yield of Cucurbita pepo. International Journal Agriculture Biology, v.14, n.4, p.641-644, 2012. http://www.fspublishers.org/ published_papers/24637_..pdf 
LIMA NETO, S. Pré-melhoramento de abóbora (Cucurbita moschata Duch.) visando biofortificação em carotenoides. Tese (Doctor scientiae). Viçosa, MG: UFV, 2013. 96p. http://textbr.123dok.com/document/lzg85o2y-premelhoramento-de-abobora-cucurbita-moschataduch-visando-biofortificacao-emcarotenoides.html

MENDES, I.B.; SANTOS, L.J.; SOUZA, S.R.; BATISTA, G.S.; CALGARO JUNIOR, G.; CUSTÓDIO, A.M.; SANTOS, L.C.; PAIM, T.P.; ALVES, E.M. Desempenho e características de acessos de abóboras (Cucurbita moschata).

Revista Eletrônica Interdisciplinar, v.1, n.17, p.1-6, 2017. http://

revista.univar.edu.br/index.php/interdisciplinar/ article/view/585

RAMOS, S.R.R.; LIMA, N.R.S.; ANJOS, J.L.; CARVALHO, H.W.L. Aspectos técnicos do cultivo da abóbora na região

Nordeste do Brasil. Aracaju: Embrapa

Tabuleiros Costeiros, (Série Documentos, 154). 2010.36p. http://www.cpatc.embrapa.br/ publicacoes_2010/doc_154.pdf

RESENDE, G.M.; BORGES, R.M.E.; GONÇALVES, N.P.S. Produtividade da cultura da abóbora em diferentes densidades de plantio no Vale do São Francisco. Horticultura Brasileira, v. 31 , n.3, p.504-508, 2013. http://www.scielo.br/pdf/ $\mathrm{hb} / \mathrm{v} 31 \mathrm{n} 3 / 27 . \mathrm{pdf}$

RIBEIRO, A.C.; GUIMRÃES, P.T.G.; ALVAREZ V., V.H. (Eds). Recomendações para uso de corretivos e fertilizantes em Minas Gerais - $5^{\text {a }}$ A proximação. Viçosa, Universidade Federal de Viçosa-MG, 1999. 359p.
RODRIGUEZ-AMAYA, D.B.; KIMURA, M.; AMAYA-FARFAN, J. Fontes Brasileiras de Carotenóides: Tabela brasileira de composição de carotenoides em alimentos. 2.ed. Brasília: Ministério do Meio Ambiente, 2008. 99p. http:// www.mma.gov.br/estruturas/sbf_agrobio/ publicacao/89_publicacao09032009113306.pdf

SANTOS, J.O.; RODRIGUES, R.; LEAL, N.R.; SUDRÉ, C.P.; FERREIRA, R.T.; LIMA, F.H. Estabilidade fenotípica em abóbora. Horticultura Brasileira, v.33, n.4 p.498-503, 2015. http:// dx.doi.org/10.1590/S0102-053620150000400015

SHI, X.; WU, H.; SHI, J.; XUE, S.J.; WANG, D.; WANG, W. CHENG, A.; GONG, Z.; CHEN, X.; WANG, C. Effect of modifier on the composition and antioxidant activity of carotenoid extracts from pumpkin (Cucurbita maxima) by supercritical $\mathrm{CO}_{2}$. Food Science and Technology, v.51, n.2, p.433-440, 2013. https://doi.org/10.1016/ j.lwt.2012.11.003

SILVA, F.A.S.; AZEVEDO, C.A.V. The Assistat Software Version 7.7 and its use in the analysis of experimental data. African Journal

Agricultural Research, v.11, n.39, p.37333740, 2016. http://www.academicjournals.org/journal/ AJAR/article-full-text-pdf/5E8596460818

SOUZA, C.O.; MENEZES, J.D.S.; RAMOS NETO, D.C.; ASSIS, J.G.A.; SILVA, S.R.; DRUZIAN, J.I.

Carotenoides totais e vitamina A de cucurbitáceas do Banco Ativo de Germoplasma da Embrapa Semiárido. Ciência Rural, CR-4480, 2012.

VERONEZI, C.M.; JORGE, N. Aproveitamento de sementes de abóbora (Cucurbita sp) como fonte alimentar. Revista Brasileira de Produtos Agroindustriais, v.14, n.1, p.113-124, 2012. http:/ /www.deag.ufcg.edu.br/rbpa/rev141/Art1410.pdf

Recebido para publicação em 8/2/2018 e aprovado em 18/6/2018.

Revista Brasileira de Agropecuária Sustentável (RBAS), v.8, n.2, p.71-76, Junho, 2018 